\title{
COMPARATIVE EVALUATION OF CHLORHEXIDINE AND SODIUM HEXAMETAPHOSPHATE MOUTH RINSES ON DENTAL PLAQUE IN CHILDREN: A RANDOMIZED CLINICAL TRIAL
}

\author{
Diana Sabri Hedihed ${ }^{1}$, Mohamed Sherif Farag², Shadeed Gad Abdelrahman ${ }^{3}$, \\ Shaimaa Mohamed Omer ${ }^{4}$, Asmaa Abd-elkariem Hashem ${ }^{5}$
}

DOI: $10.21608 / d s u .2020 .13848 .1002$

\section{KEYWORDS}

Chlorhexidine;

Dental plaque;

Lactobacillus;

Sodium Hexametaphosphate;

Streptococcus mutans.
- E-mail address: dianasabri11@gmail.com

1. B.D.S., General Dental Practioner in the Ministry of Health.

2. Professor of Pediatric and Preventive Dentistry and Dental Public Health, Faculty of Dentistry, Suez Canal University

3. Associate Professor of Pharmaceutics and Industrial Pharmacy, Faculty of Pharmacy Suez Canal University

4. Lecturer of Pediatric and Preventive Dentisrty and Dental Puplic Health, Faculty of Dentistry - Suez Canal University

5. Lecturer of Medical Microbiology and Immunology, Faculty of Medicine- Suez Canal University

\begin{abstract}
Introduction: The use of a mouthwash augments mechanical removal of plaque by brushing and flossing and helps maintain oral health through its antiplaque and antibacterial chemical properties. Aim: to evaluate and compare clinically and microbiologically the effectiveness of chlorhexidine and sodium hexametaphosphate mouth rinses on dental plaque in children. Materials and methods: This randomized clinical trial included 40 normal apparently healthy and cooperative children aged 8 to 10 years and selected from the outpatient dental clinic of Pediatric Dentistry Department, Faculty of Dentistry, Suez Canal University. Children were randomly divided into 2 groups as follows: Group I: included (20) children who rinsed with Chlorhexidine (0.2\%) and Group II: included (20) children who rinsed with Sodium Hexametaphosphate (7\%). Clinical evaluation was performed by measuring gingival and plaque indices scores at all evaluation periods. Microbiological evaluation was performed by direct examination of bacterial cultures. Results: Sodium hexametaphosphate $7 \%$ mouth rinse showed a superior effect compared to chlorhexidine $0.2 \%$ mouth rinse in terms of improvement in the clinical scores and decreasing the microbial counting. Conclusion: Sodium hexametaphosphate $7 \%$ mouth rinse is a promising candidate of mouthwashes.
\end{abstract}

\section{INTRODUCTION}

Dental plaque is a biofilm that is naturally found on surfaces of teeth and other parts of the oral cavity. It is considered as the primary etiological factor for oral diseases; specially dental caries and periodontal diseases. ${ }^{(1)}$

Mechanical plaque control is the mainstay for prevention of oral diseases, but it requires patient cooperation and motivation; therefore, chemical plaque control is used for achieving the desired results. ${ }^{(2)}$ Chemotherapeutic agents may be used to reduce, eliminate or change the quality of microbial pathogens. In addition, they alter the host response through local or systemic delivery of appropriate agents. ${ }^{(3)}$ Chlorhexidine is one of the most frequently used compounds. It is a broad spectrum antiseptic with pronounced antimicrobial effects on both Gram-positive as well as Gram-negative bacteria and some viruses. ${ }^{(4)}$

Chlorhexidine remains in the oral cavity several hours after application that makes it a useful agent for prevention of plaque regrowth and bacterial colonization. ${ }^{(5)}$ 
On the other hand, chlorhexidine has some disadvantages; it irritates the oral mucosa and this is not dosage dependent. Tooth discoloration, sensitivity changes, taste perturbation, unilateral, or bilateral parotid swelling and tongue pain may occur as side effects leading to search for new formulations. ${ }^{(6)}$

The addition of inorganic polyphosphate salts (including sodium hexametaphosphate) to fluoridated products has been shown to be effective in increasing their effectiveness against caries. ${ }^{(7)}$ Sodium hexametaphosphate (SHMP) is able to inhibit the formation of dental calculus, ${ }^{(8)}$ has antimicrobial action ${ }^{(9)}$ and also prevents the formation of extrinsic stains. SHMP has greater possibility of binding to the enamel surface and protecting it from acid dissolution. ${ }^{(10)}$

Our study aimed to compare and evaluate the effect of chlorhexidine and sodium hexametaphosphate mouth rinses on dental plaque in children.

\section{MATERIALS AND METHODS}

This study was a randomized clinical trial involving 40 normal apparently healthy and cooperative children aged from 8-10 years from both sexes from those attending outpatient dental clinic of Pediatric and Preventive Dentistry and Dental Public Health Department, Faculty of Dentistry, Suez Canal University. Adequate diagnosis and treatments planning were performed. Each selected child was subjected to full mouth treatments if needed until we had all the selected patients with no caries.

\section{Inclusion criteria:}

1. Either caries free children or previously treated children.

2. Age from 8-10 of both sexes.

3. Apparently healthy children.
4. No systemic diseases, children took antibiotic, steroid therapy or any anti-inflammatory drugs for the last 3 weeks.

5. With full eruption of upper left permanent first molar, upper left permanent lateral incisor, upper right primary first molar, lower right permanent first molar, lower right permanent lateral incisor and lower left primary first molar.

\section{Exclusion criteria:}

1. Children with orthodontic appliances or with intra oral prosthesis.

2. Un cooperative children or children who cannot attend the follow up visits.

3. Children had a history of fluoride treatment in the past 2 weeks.

4. Children had a history of allergies to any dental products or their ingredients.

5. Patients with missing upper left permanent first molar or upper left permanent lateral incisor or upper right primary first molar or lower right permanent first molar or lower right permanent lateral incisor or lower left primary first molar.

Informed consent, both written and verbal, was obtained from both the parent and the children before enrolling in the study. Each child was instructed to brush his or her teeth with a toothbrush wetted with water using Stillman's brushing technique. Tooth brushing technique and mouth rinsing method were demonstrated for every child. Children were instructed to brush and rinse twice daily in the morning and evening for two weeks. They were instructed to rinse with $15 \mathrm{ml}$ of the solution for $1 \mathrm{~min}$ followed by expectoration of the residual mouth rinse and they were asked not to eat or drink anything for $30 \mathrm{~min}$ after using the mouthwash for collection of plaque samples. During the treatment period there was not any other oral hygiene measure. ${ }^{(11,12)}$ 
Children were randomly divided into 2 groups as follows:

- Group I: included (20) children who rinsed with Chlorhexidine $(0.2 \%)$.

- Group II: included (20) children who rinsed with Sodium Hexametaphosphate (7\%).

\section{Preparation of chlorhexidine $(0.2 \%)$ mouth wash:}

Mouth wash containing chlorhexidine was formulated by the following formula. ${ }^{(13)} \mathrm{A}$ calculated amount of surfactant was heated and transferred to the main container. Sorbitol was diluted with distilled water and added to the main container. In other containers, Sodium benzoate and Sodium saccharine were dissolved, filtered and added to the main container. Chlorhexidine was diluted with water, filtered and added to the main container. Finally flavouring agent and colour were dissolved separately, filtered and added to the main container. The total volume was adjusted using distilled water. The final product was analyzed and filled in suitable bottles.

\section{Preparation of Sodium Hexametaphosphate (7\%) mouth wash:}

Mouth wash containing Sodium hexametaphosphate was formulated by the following formula. ${ }^{(13)}$ A calculated amount of surfactant was heated and transferred to the main container. Sorbitol was diluted with distilled water and added to the main container. In other containers, Sodium benzoate and Sodium saccharine were dissolved, filtered and added to the main container. Sodium hexametaphosphate was diluted with water, filtered and added to the main container. Finally, flavouring agent and colour were dissolved separately, filtered and added to the main container. The total volume was adjusted using distilled water. The final product was analyzed and filled in suitable bottles.

\section{Methods of evaluation:}

All children were evaluated clinically and microbiologically a day before using mouth washes (as the base line in each group as control) then at 7 th and 15th day after mouth rinsing.

\section{A- Clinical evaluation:}

Clinical evaluation by measuring gingival and plaque indices scores was done as follows:

\section{Gingival index: ${ }^{(14)}$}

Gingival index was used by Loe and Silness to assess gingival condition and record qualitalization changes in the gingiva. The examination was done by blunt probe and partially erupted teeth were excluded. The selected teeth were upper left permanent first molar, upper left permanent lateral incisor, upper right primary first molar, lower right primary first molar. The selected surfaces were buccal, lingual, mesial and distal.

\section{( Modification of the Quigley Hein Plaque Index ): ${ }^{(15)}$}

A disclosing agent was used for plaque detection. Children were instructed to rinse with the disclosing agent. The selected teeth were the same used above in the gingival index. Plaque was assessed on the labial, buccal and lingual surfaces of the teeth after using a disclosing agent.

\section{B- Microbiological analysis}

\section{I- Collection of specimens:}

Sterile cotton swab fixed on a wooden stick was streaked across the entire labial tooth surface of the lower anteriors (incisors) from distal to mesial in a horizontal direction while exerting pressure on the swab getting as close as possible to the gingival 
margin without touching it (supragingival plaque). All the samples were aseptically processed and tested for the isolation, identification and colony counts of Streptococcus mutans and Lactobacillus species.

\section{II-Streptococcus mutans isolation and identification:}

Streptococcus mutans are facultative anaerobic Gram-positive coccus-shaped bacteria and their optimal growth is at $37^{\circ} \mathrm{C}$. On mitis salivarius agar, Streptococcus mutans colonies are small, raised, irregularly margined and adherent. ${ }^{(16,17)}$

\section{Preparation of mitis salivarius bacitracin (MSB) agar:}

Mitis salivarius agar was used to selectively enumerate Streptococcus mutans in swaps from dental plaque. ${ }^{(18)}$ The MSB medium was prepared according to the instructions of the manufacturer.

\section{III-Lactobacilli isolation and identification:}

Lactobacilli are long, slender, non-spore forming, Gram-positive rods that are generally facultative anaerobic, most of which grow well with reduced oxygen tension and increased $\mathrm{CO} 2$. Lactobacilli grow on a variety of media including Rogosa agar where they appear as white, usually mucoid colonies. ${ }^{(19)}$

\section{Preparation of Rogosa agar:}

Rogosa agar was used to selectively enumerate lactobacilli in the swaps from dental plaque. ${ }^{(20)}$ The medium was prepared according to the instructions of the manufacturer.

\section{I $V$-Processing of the Specimens:}

1. Swabs were placed into tubes containing $5 \mathrm{ml}$ tryptone soya broth. Samples were vortexed for 30 seconds to mix them thoroughly.
2. For quantitative bacterial assessment, sterile disposable calibrated loops $1 / 100$ and $1 / 1000$ $\mathrm{ml}$ were used to transfer and streak swab specimens into freshly prepared MSB and Rogosa agar plates.

3. (MSB ) agar plates were incubated anaerobically at $37^{\circ} \mathrm{C}$ for $48-72$ hours.

4. Rogosa agar plates were incubated anaerobically in anaerobic jar using anaerobic gas pack and plates were incubated at $37^{\circ} \mathrm{C}$ for $48-72$ hours.

5. After incubation, a colony counter with magnifying glass was used to count the number of colonies and they were expressed as the number of colony forming units per $\mathrm{ml}(\mathrm{CFU} / \mathrm{ml})$ of sample. By multiplying the actual colony count by $10^{2}$ or $10^{3}$ (according to the used calibrated loop) quantification of the number of colonies was done. ${ }^{(21)}$

\section{Statistics:}

Statistical presentation and analysis of the present study was conducted, using the mean, standard deviation, student t-test, Paired t-test by SPSS V20.

Unpaired Student T-test was used to compare between two groups in quantitative data.

\section{RESULTS}

\section{Clinical results}

Evaluation of clinical parameters (gingival and plaque indices scores) was done for all the treated groups at baseline, 7 day and 15 day according to the gingival index system and Turesky et al Modified Quigley Hein Plaque Index system respectively. 


\subsection{Gingival index results:}

Group I and group II showed a decrease in the mean value of gingival index form baseline to 7 days, from 7 days to 15 days and from baseline to 15 days. This decrease was highly statisticallysignificantly different as shown in table (1).
In between groups, there was a highly statistical significant decrease in the mean of gingival index when comparing between group II and group I at all evaluation periods (after 7 days and 15 days) as shown in table (1).

Table (1): Comparison between mean values of gingival index in group I and group II measured at different times of evaluation.

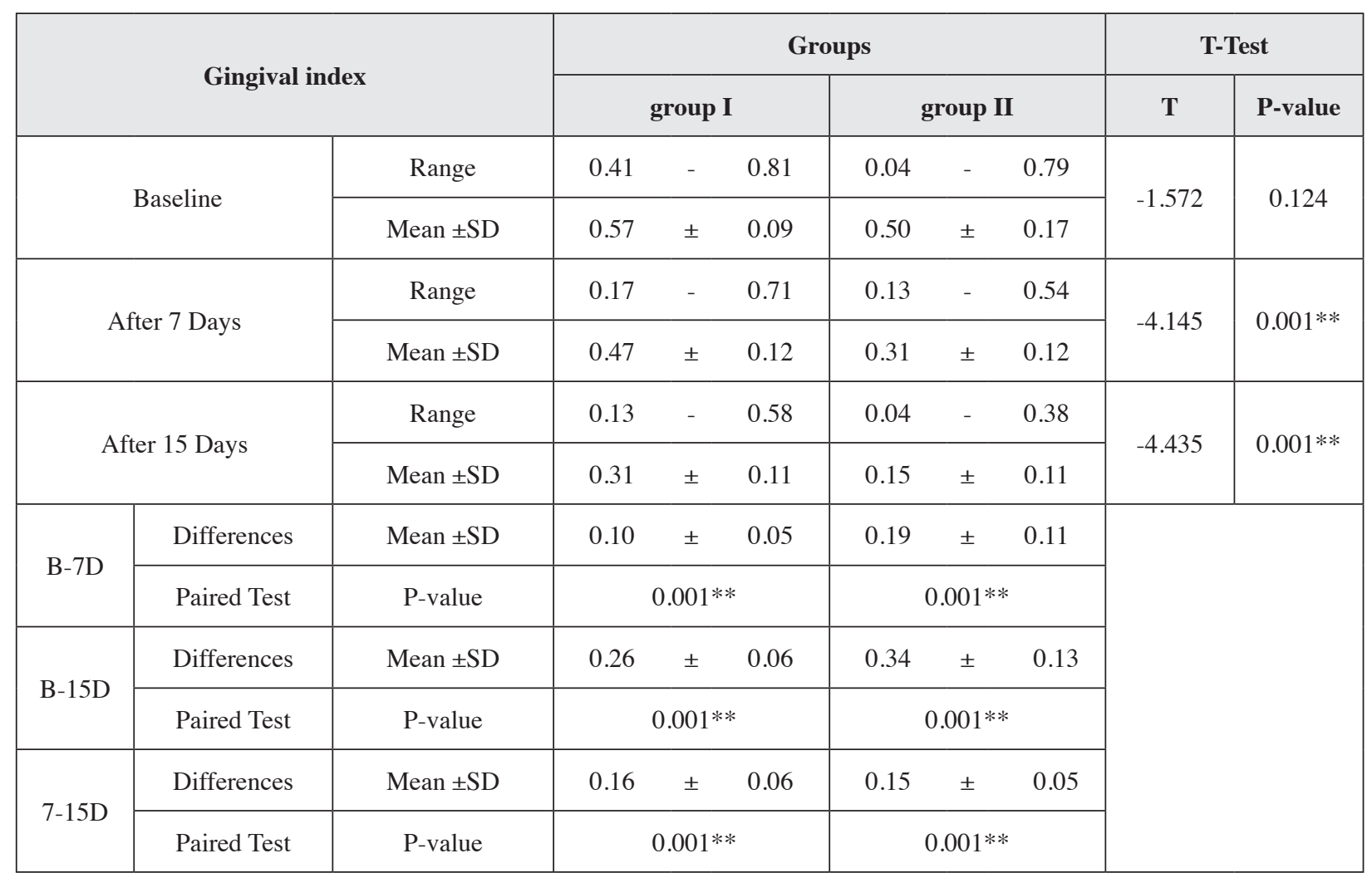

The group I = Chlorhexidine group - The group II = Sodium Hexametaphosphate group

$P$-value $>0.05$ Non significant

$*$ P-value $\leq 0.05$ Significant

$* * P$-value $<0.01$ Highly Significant 


\subsection{Turesky et al. Modified Quigley Hein Plaque Index results:}

Group I and Group II showed a decrease in the mean value of plaque index form baseline to 7 days, from 7 days to 15 days and from baseline to 15 days. This decrease was highly statistically significantly different as shown in table (2) and figures $(1,2)$.
In between groups, at the 7th day there was a statistical significant decrease* in the mean value of plaque index in group II when compared with its corresponding value in group I.

At the 15 th day there was highly statistically significant decrease in the mean value of plaque index in group II when compared with its corresponding value in group I as shown in table (2).

Table (2): Comparison between mean values of Turesky et al Modified Quigley Hein Plaque Index in the group I and group II measured at different times of evaluation.

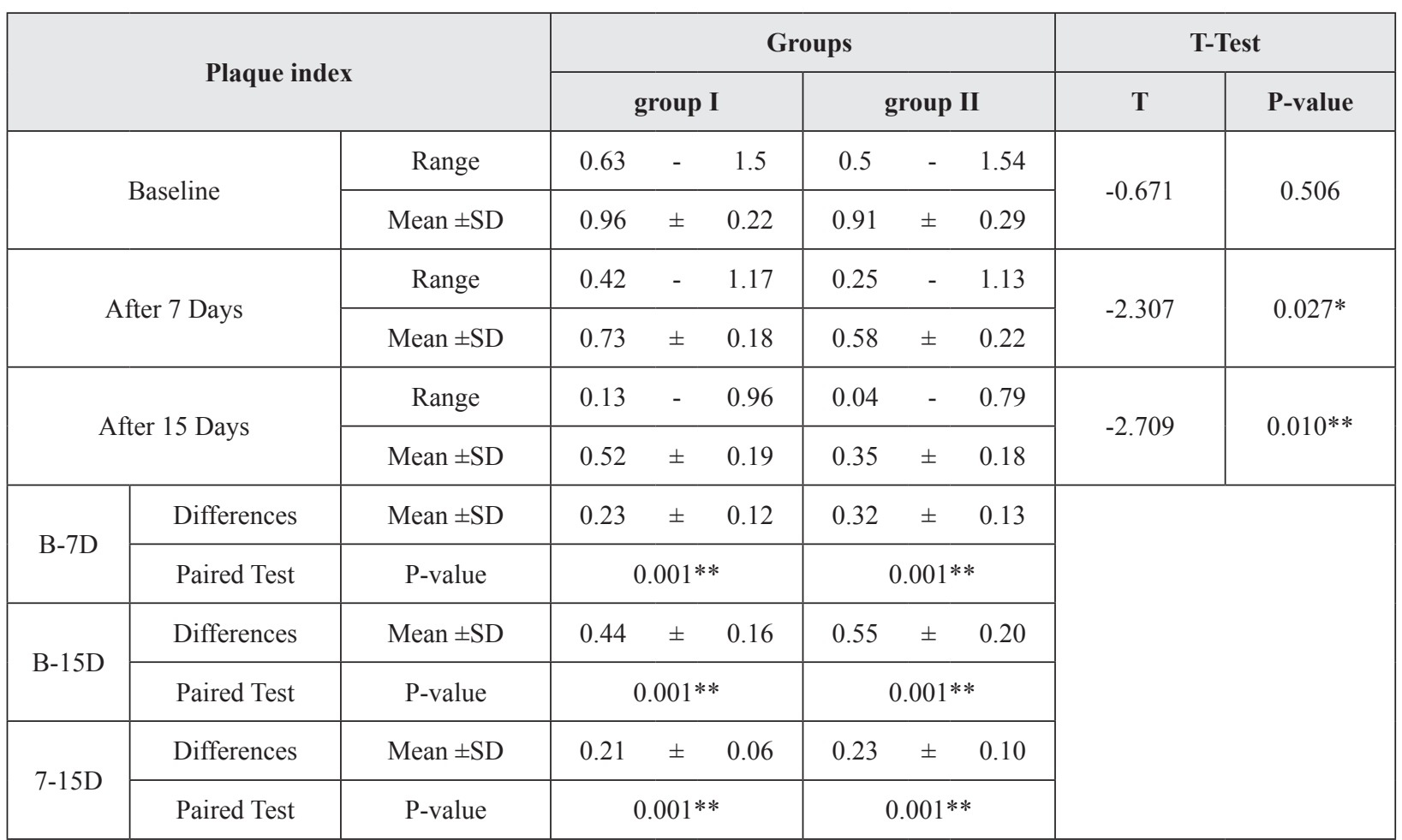

The group I = Chlorhexidine group, group I = Sodium Hexametaphosphate group

$P$-value $>0.05$ Non significant

$* P$-value $\leq 0.05$ Significant

**P-value <0.01 Highly Significant 


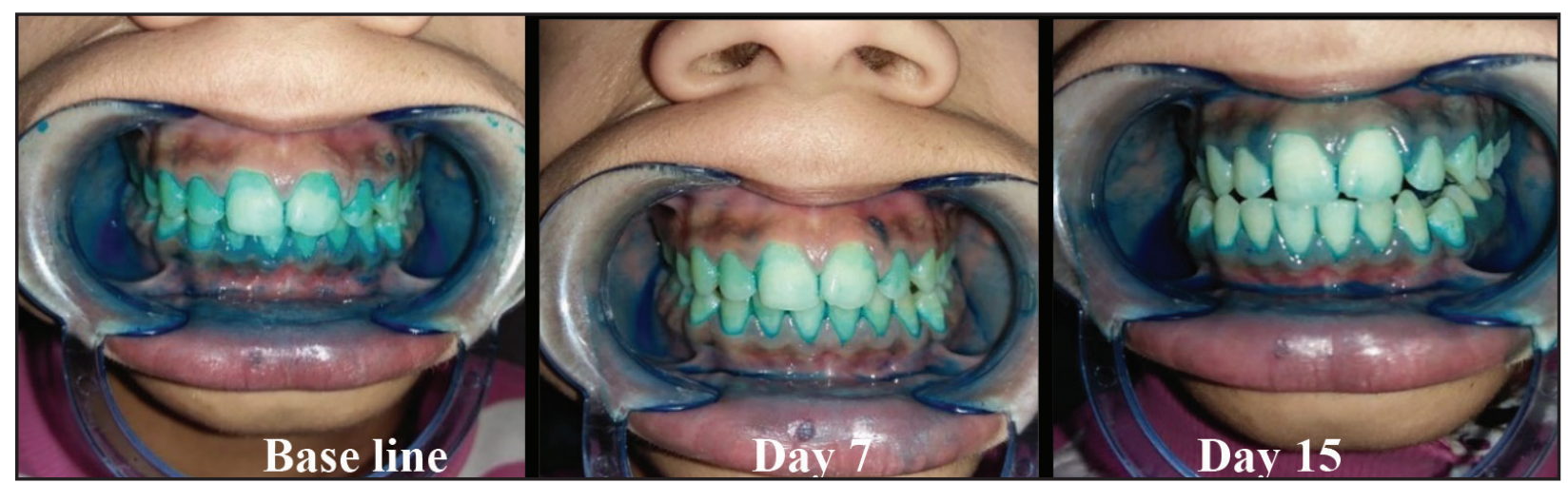

Fig. (1) Photographs showing patient 10 years old showing staining of microbial biofilm in dental plaque with disclosing agent at base line, day 7 and day 15 (group I).

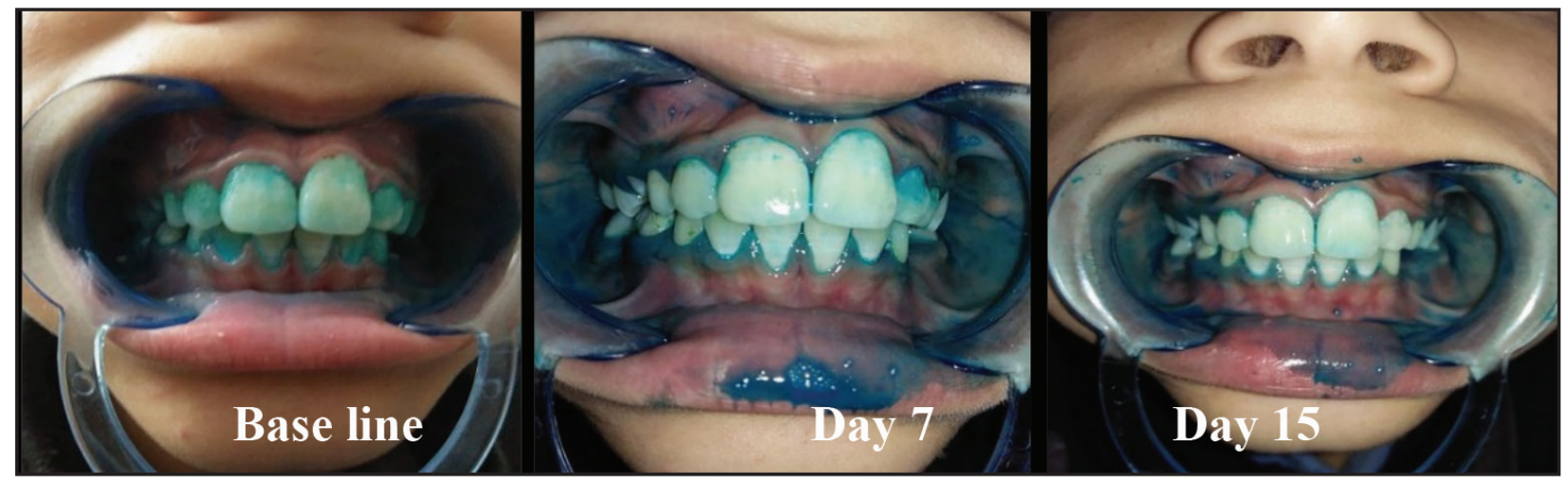

Fig. (2) Photographs showing patient 10 years old showing staining of microbial biofilm in dental plaque with disclosing agent at base line, day 7 and day 15 (group II).

\section{Microbiological results}

\subsection{Streptococcus mutans count:}

The mean value of $S$. mutans count in both group I and group II showed a highly statistically significant decrease from 7 days to 15 days and from baseline to 15 days as shown in table (3) and figures $(3,4)$.

In between groups, there was a highly statistical significant decrease in the mean of $S$. mutans count when comparing between group II and group I at all evaluation periods (after 7 days and 15 days) as shown in table (3).

\subsection{Lactobacillus count:}

The mean value of Lactobacillus count in both group I and group II showed a highly statistically significant decrease from 7 days to 15 days and from baseline to 15 days as shown in table (4) and figures $(5,6)$.

In between groups, there was no statistical significant difference in the mean value of Lactobacillus count when comparing between group II and group I at all evaluation periods (after 7 days and 15 days) as shown in table (4). 
Table (3): Comparison between S. mutans count in group I and group II measured at different times of evaluation.

\begin{tabular}{|c|c|c|c|c|c|c|c|c|c|c|}
\hline \multirow{2}{*}{\multicolumn{3}{|c|}{ S. Mutants count }} & \multicolumn{6}{|c|}{ Groups } & \multicolumn{2}{|c|}{ T-Test } \\
\hline & & & \multicolumn{3}{|c|}{ Group I } & \multicolumn{3}{|c|}{ group II } & $\mathbf{t}$ & P-value \\
\hline \multirow{2}{*}{\multicolumn{2}{|c|}{ Baseline }} & Range & 4.6 & - & 5.08 & 4.48 & - & 5.18 & \multirow{2}{*}{0.635} & \multirow{2}{*}{0.529} \\
\hline & & Mean \pm SD & 4.90 & \pm & 0.15 & 4.94 & \pm & 0.20 & & \\
\hline \multirow{2}{*}{\multicolumn{2}{|c|}{ After 7 Days }} & Range & 4 & - & 5 & 3.3 & - & 4.7 & \multirow{2}{*}{-4.596} & \multirow{2}{*}{$0.001 * *$} \\
\hline & & Mean \pm SD & 4.75 & \pm & 0.30 & 4.11 & \pm & 0.54 & & \\
\hline \multirow{2}{*}{\multicolumn{2}{|c|}{ After 15 Days }} & Range & 3.7 & - & 4.95 & 2.7 & - & 4.48 & \multirow{2}{*}{-6.374} & \multirow{2}{*}{$0.001 * *$} \\
\hline & & Mean \pm SD & 4.41 & \pm & 0.49 & 3.36 & \pm & 0.54 & & \\
\hline \multirow{2}{*}{ B-7D } & Differences & Mean \pm SD & 0.14 & \pm & 0.37 & 0.82 & \pm & 0.48 & & \\
\hline & Paired Test & P-value & \multicolumn{3}{|c|}{0.097} & \multicolumn{3}{|c|}{$0.001 * *$} & & \\
\hline \multirow{2}{*}{ B-15D } & Differences & Mean \pm SD & 0.49 & \pm & 0.53 & 1.57 & \pm & 0.53 & & \\
\hline & Paired Test & P-value & \multicolumn{3}{|c|}{$0.001 * *$} & \multicolumn{3}{|c|}{$0.001 * *$} & & \\
\hline \multirow{2}{*}{$7-15 \mathrm{D}$} & Differences & Mean \pm SD & 0.35 & \pm & 0.43 & 0.75 & \pm & 0.34 & & \\
\hline & Paired Test & P-value & \multicolumn{3}{|c|}{$0.002 * *$} & \multicolumn{3}{|c|}{$0.001 * *$} & & \\
\hline
\end{tabular}

The group $I=$ Chlorhexidine group, group II = Sodium Hexametaphosphate group

$P$-value $>0.05$ Non significant $* P$-value $\leq 0.05$ Significant $\quad * * P$-value $<0.01$ Highly Significant

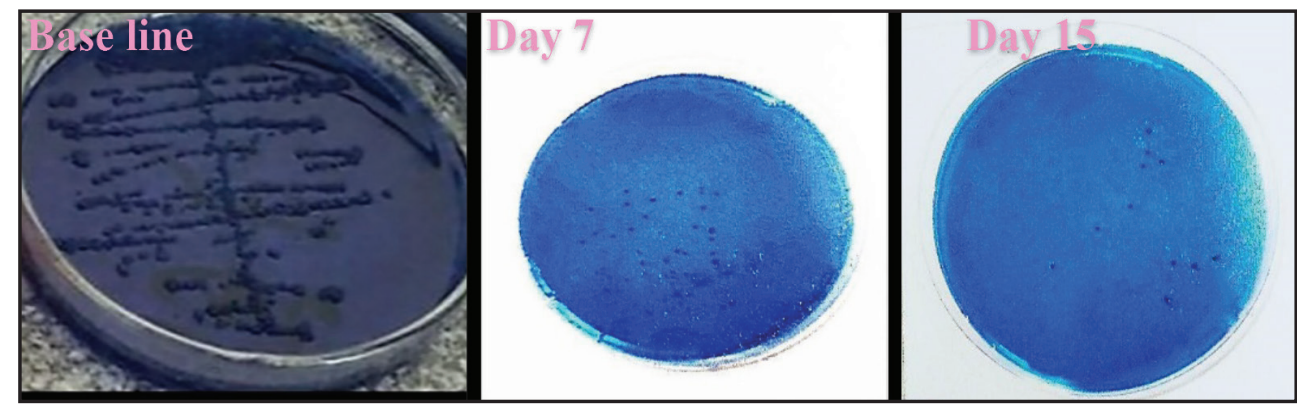

Fig. (3) Photographs showing Streptococcus mutans colony growth on Mitis salivarius bacitracin agar (MSB) at base line, day 7 and day 15 (group I).

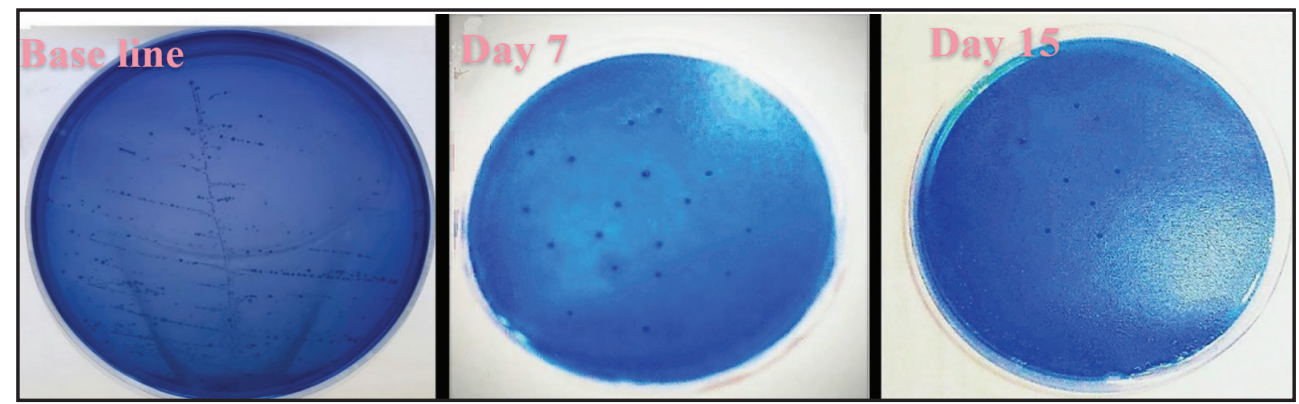

Fig. (4) Photographs showing Streptococcus growth colony on Mitis salivarius bacitracin agar (MSB) at base line, day 7 and day 15 (group II). 
Table (4): Comparison between Lactobacillus count in group I and group II measured at different times of evaluation.

\begin{tabular}{|c|c|c|c|c|c|c|c|c|c|c|}
\hline \multirow{2}{*}{\multicolumn{3}{|c|}{ Lactobacillus count }} & \multicolumn{6}{|c|}{ Groups } & \multicolumn{2}{|c|}{ T-Test } \\
\hline & & & \multicolumn{3}{|c|}{ group I } & \multicolumn{3}{|c|}{ Group II } & $\mathrm{t}$ & P-value \\
\hline \multirow{2}{*}{\multicolumn{2}{|c|}{ Baseline }} & Range & 3.7 & - & 4.9 & 4 & - & 5 & \multirow{2}{*}{1.579} & \multirow{2}{*}{0.123} \\
\hline & & Mean \pm SD & 4.44 & \pm & 0.46 & 4.64 & \pm & 0.32 & & \\
\hline \multirow{2}{*}{\multicolumn{2}{|c|}{ After 7 Days }} & Range & 3.3 & - & 4.88 & 2.99 & - & 4.7 & \multirow{2}{*}{-1.901} & \multirow{2}{*}{0.065} \\
\hline & & Mean \pm SD & 4.25 & \pm & 0.51 & 3.90 & \pm & 0.63 & & \\
\hline \multicolumn{2}{|c|}{ After 15 Days } & Range & 2.7 & - & 3.7 & 2.7 & - & 3.48 & \multirow{2}{*}{-0.951} & \multirow{2}{*}{0.348} \\
\hline & $\mathrm{n} \pm \mathrm{SD}$ & Mean \pm SD & 3.07 & \pm & 0.4 & 2.97 & \pm & 0.27 & & \\
\hline \multirow{2}{*}{ B-7D } & Differences & Mean \pm SD & 0.20 & \pm & 0.20 & 0.74 & \pm & 0.36 & & \\
\hline & Paired Test & P-value & \multicolumn{3}{|c|}{$0.001 * *$} & \multicolumn{3}{|c|}{$0.001 * *$} & & \\
\hline \multirow{2}{*}{ B-15D } & Differences & Mean \pm SD & 1.37 & \pm & 0.58 & 1.67 & \pm & 0.35 & & \\
\hline & Paired Test & P-value & \multicolumn{3}{|c|}{$0.001 * *$} & \multicolumn{3}{|c|}{$0.001 * *$} & & \\
\hline \multirow{2}{*}{$7-15 \mathrm{D}$} & Differences & Mean \pm SD & 1.17 & \pm & 0.61 & 0.93 & \pm & 0.65 & & \\
\hline & Paired Test & P-value & \multicolumn{3}{|c|}{$0.001 * *$} & \multicolumn{3}{|c|}{$0.001 * *$} & & \\
\hline
\end{tabular}

The group I = Chlorhexidine group, group II = Sodium Hexametaphosphate group

$P$-value $>0.05$ Non significant

$* P$-value $\leq 0.05$ Significant

$* * P$-value $<0.01$ Highly Significant

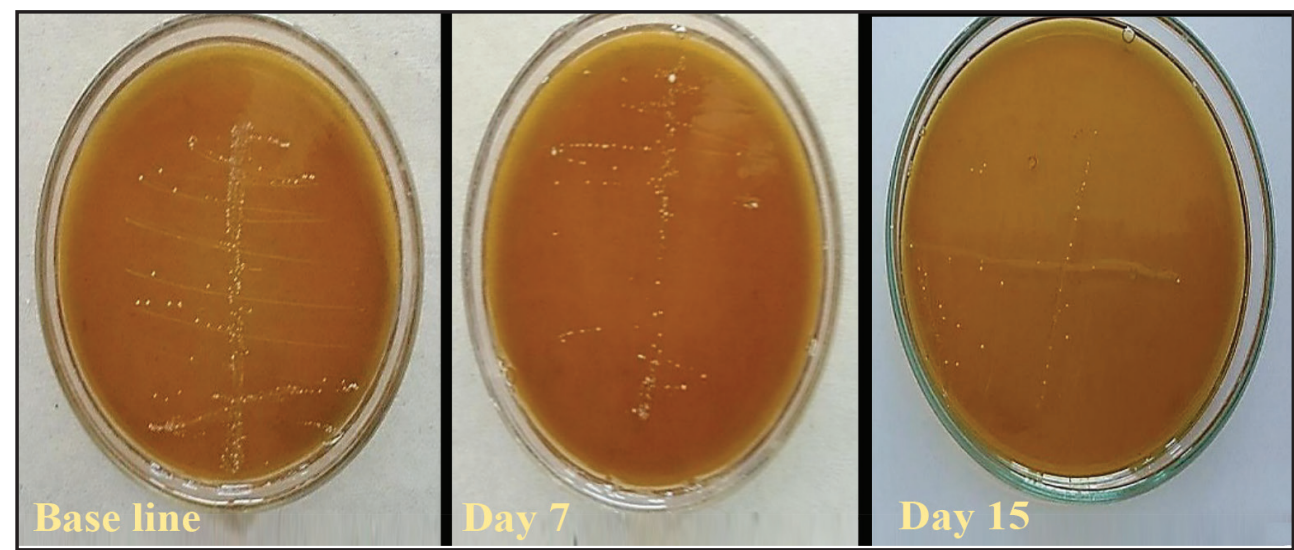

Fig. (5) Photographs showing Lactobacillus colony growth on Rogosa agar at base line, day 7 and day 15 (group I).

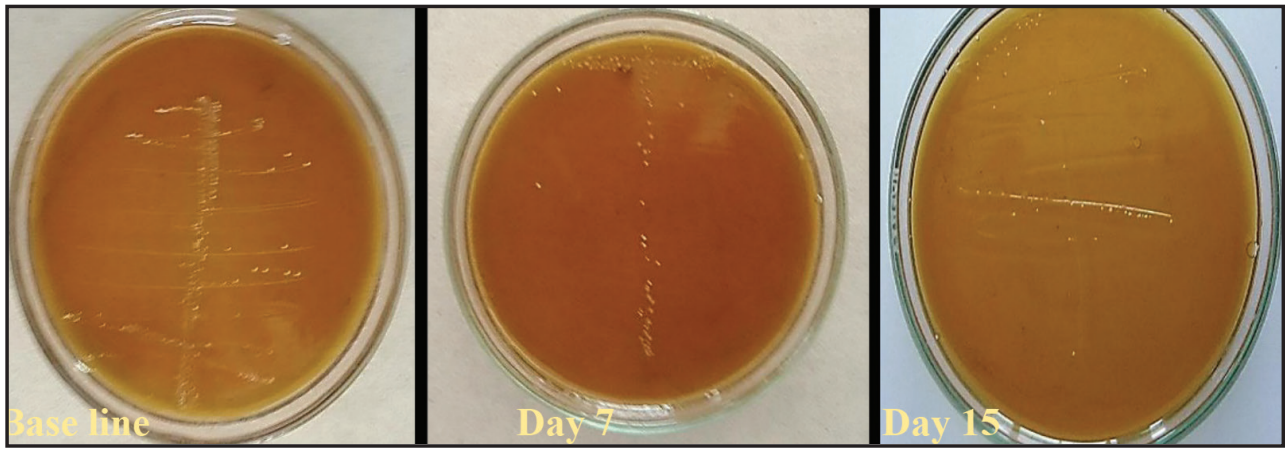

Fig. (6) Photographs showing Lactobacillus colony growth on Rogosa agar at base line, day 7 and day 15 (group II).

VOL. 1 - NO. 1 


\section{DISCUSSION}

Dental plaque is a deposition that comprised of numerous living species of microorganisms embedded in an extracellular matrix. Formation of dental plaque is a progressive and dynamic process, which may result in the establishment of caries and gingivitis. Streptococcus mutans and lactobacilli are the main components of dental plaque. ${ }^{(22)}$

In order to prevent mouth diseases, plaque control is performed by regular mechanical means and chemical agents, which act specifically against those microorganisms. ${ }^{(23)}$

Chlorhexidine was used as a mouthwash because it is considered the gold standard anti plaque agent against which efficacy of other anti-plaque and anti-gingivitis agents is measured. In addition, it provides immediate bactericidal and prolonged bacteriostatic action due to adsorption onto the pellicle-coated enamel surface. ${ }^{(24,25)}$

In this study, Sodium Hexametaphosphate (SHMP) was used because it is a non-combustible material with no significant environmental effects. It has a low oral toxicity and may cause minor irritation to skin, eyes and respiratory tract. ${ }^{(26)}$

Clinical results of this study demonstrated that gingival and plaque indices scores among treated children with SHMP mouth rinse had statistical significant improvement compared to the group treated with chlorhexidine mouth rinse at all evaluation periods ( 7 days and 15 days).

The effect of chlorhexidine on plaque and its property of slow release have made it as the panacea in the adjunctive treatment to gingivitis. Chlorhexididne being cationic prevents pellicle formation and is bacteriostatic at lower concentrations and bactericidal at higher concentrations. ${ }^{(27)}$
Bellamy et al. ${ }^{(28)}$ stated that when SHMP added to a stabilized stannous fluoride dentifrice provides the additional benefits of prevention of calculus formation, stain removal and reduction of stain formation and plaque formation.

Microbiological results of this study revealed that the mean value of $S$. mutans count showed a statistical significant decrease when comparing between group II and group I at all evaluation periods (7 days and 15 days).This may be due to the potent antimicrobial activity of SHMP.

Antibacterial effect of SHMP 7\% mouthwash against $S$. mutans and lactobacillus were better than that produced by chlorhexidine $0.2 \%$ mouthwash. Many studies showed that (SHMP) inhibits the growth of streptococci mutans resulting in a decrease of plaque formation and dental caries. ${ }^{(29)}$

On other hands, SHMP does not generally exert any adverse effect on the body when used locally and orally within the range of minimum inhibitory concentrations (MICs) determined for various bacteria. ${ }^{(30)}$ In addition, Hacchou et al. ${ }^{(31)}$ found that SHMP can stimulate bone formation. Thus, SHMP seems to be a promising substance for treatment of periodontal diseases and promoting bone regeneration.

These results were in agreement with Murphy et al. ${ }^{(32)}$, Da Camara et al. ${ }^{(33)}$ who proved that SHMP is characterized by potent, and various biological properties including efficient anti-microbial and anti-biofilm actions. SHMP probably have multiple mechanisms of antibacterial action.

The antimicrobial activity of SHMP can be explained by a mechanism suggested by Maier et al. ${ }^{(34)}$ as SHMP may inhibit the microorganisms by forming potentially inhibitory compounds 
(e.g., superoxide) or disrupting intracellular metabolism or protein folding. ${ }^{(35)}$

In addition, Shibata et al. ${ }^{(36)}$ and Knabel et al. ${ }^{(37)}$ reported that the antibacterial effect of SHMP against Gram-positive bacteria, including Streptococci mutans, is related to its ability to chelate divalent cations resulting in cell division inhibition and loss of cell wall integrity. SHMP induces direct lysis of Staphylococcus aureus (S. aureus) by chelation of structurally essential metal ions in their membranes. ${ }^{(38,39)}$

Also, the antimicrobial action of SHMP is related to its capacity to increase the permeability of the bacteria and glucose transport when it links to the $\mathrm{Mg}+$ present in the outer membrane. ${ }^{(40)}$

These results were in agreement with an in vitro study carried out by Post et al. ${ }^{(41)}$ in which the influence of SHMP on selected bacteria was assessed. The results showed that most Gram-positive bacteria were prevented from growing on medium containing $0.1 \%$ SHMP and Gram-negative bacteria were capable of growing in higher concentrations even up to $10 \%$ SHMP.

In addition, another study in 2008 carried out by Obritsch et al. ${ }^{(42)}$ in which the sensititvity of Gramnegative (Escherichia coli [E. coli] and Salmonella Typhimurium) and Gram-positive (Bacillus subtilis, Staphylococcus aureus, Lactobacillus plantarum and Listeria monocytogenes) spoilage and pathogenic bacteria to different members of long-chain polyphosphates including SHMP was tested. The results showed that Gram-positive bacteria are more sensitive to polyphosphates than are Gram-negative bacteria, possibly because of the differences in cell wall structure.

\section{CONCLUSIONS}

1. SHMP mouthwash at a concentration of $7 \%$ had superior antibacterial effects.

2. SHMP $7 \%$ mouthwash improved the clinical parameters than chlorhexidine $0.2 \%$ mouthwash regarding gingival and plaque scores.

3. SHMP 7\% mouthwash decreased the microbial count of Streptococcus mutans and Lactobacillus species than chlorhexidine $0.2 \%$ mouthwash.

\section{REFERENCES}

1. Seneviratne CJ, Zhang CF, Samaranayake LP. Dental plaque biofilm in oral health and disease. Chin J Dent Res 2011; 14(2):87-94. https://www.ncbi.nlm.nih.gov/pubmed/22319749

2. Jafer M, Patil S, Hosmani J, Bhandi SH, Chalsserry EP, Anil S. Chemical plaque control strategies in the prevention of biofilm-associated oral diseases. J Contemp Dent Pract. 2016 1;17(4):337-343. https://www.ncbi.nlm. nih.gov/pubmed/27340170

3. Teles RP, Teles FR. Antimicrobial agents used in the control of periodontal biofilms: effective adjuncts to mechanical plaque control? Braz Oral Res. 2009;23(1):39-48. https:// www.ncbi.nlm.nih.gov/pubmed/19838557

4. Rashed HT. Evaluation of the effect of hydrogen peroxide as a mouthwash in comparison with chlorhexidine in chronic periodontitis patients: A clinical study. J Int Soc Prev Community Dent. 2016; 6(3):206-212. https://www.ncbi.nlm.nih.gov/ pmc/articles/PMC4916793/ DOI: 10.4103/2231-0762.183114

5. Mirzadeh A, Rahmani S, Sirjani M, Mirzadeh A, Salahi SA. A comparative study on the effect of $0.2 \%$ chlorhexidine mouthwash and $0.2 \%$ chlorhexidine gel on gingivitis and plaque accumulation. Bull Env Pharmacol. Life Sci. 2014;3(4):140-144. http://www.bepls.com

6. Vinod KS, Sunil KS, Sethi P, Bandla RC, Singh S, Patel D. A novel herbal formulation versus chlorhexidine mouthwash in efficacy against oral microflora. J Int Soc Prev Community Dent 2018; 8(2):184-190. https://www.ncbi. nlm.nih.gov/pmc/articles/PMC5946529/ 
7. Danelon M, Takeshita EM, Peixoto LC, Sassaki KT, Debem ACB. Effect of fluoride gels supplemented with sodium trimetaphosphate in reducing demineralization. Clin Oral Investig 2014;18:1119-1127. https://www.ncbi. nlm.nih.gov/pubmed/24061604

8. Schiff T, Saletta L, Baker RA, Winston JL, He T. Desensitizing effect of a stabilized stannous fluoride/ Sodium hexametaphosphate dentifrice. Compend Contin Educ Dent 2005; 26:35-40. https://www.ncbi.nlm.nih.gov/ pubmed/16999008

9. Vaara M. Agents that increase the permeability of the outer membrane. Microbiol Rev 1992; 56:395-411. https://www. ncbi.nlm.nih.gov/pubmed/1406489

10. Liu H, Segreto VA, Baker RA, Vastola KA, Ramsey LL, Gerlach RW. Anticalculus efficacy and safety of a novel whitening dentifrice containing sodium hexametaphosphate: A controlled six month clinical trial. J Clin Dent 2002; 13(1):25-28. https://www.ncbi.nlm.nih.gov/ pubmed/11507928

11. Surya LS, Elianora D, Fitriana A. Effective methods of brushing teeth on reducing plaque score at the fifth Class of semen padang elementary schooling indarung village lubukkilangan subdistrict, Indonesia. IJSBAR. 2015;22(1):281-86. http://gssrr.org/index.php?journal

12. Priya BM, Anitha V, Shanmugam M, Ashwath B, Suganthi D. Sylva SD, et al. Efficacy of chlorhexidine and green tea mouthwashes in the management of dental plaqueinduced gingivitis: A comparative clinical study. Contemp Clin Dent 2015;6(4):505-509. https://www.ncbi.nlm.nih. gov/pmc/articles/PMC4678549/ DOI: 10.4103/0976237X.169845

13. Allen LV, Popovich NG, Ansel HC. Ansel's Pharmaceutical Dosage Forms and Drug Delivery Systems. $8^{\text {th }}$ ed. Baltimore, Md: Lippincott Williams \& Wilkins; 2005;71 p.

14. Löe H, Silness J. Periodontal disease in pregnancy I. Prevalence and severity. Acta Odontol Scand 1963;21:533551. https://www.ncbi.nlm.nih.gov/pubmed/14121956 DOI: $10.3109 / 00016356309011240$

15. Turesky S, Gilmore ND, Glickman I. Reduced plaque formation by the chloromethyl analogue of victamine C.J Periodontol 1970; 41(1):41-3. https://www.ncbi.nlm.nih. gov/pubmed/5264376 DOI: 10.1902/jop.1970.41.41.41

16. Hamada S, Slade HD. Biology, immunology and cariogenicity of Streptococcus mutans. Microbiol
Rev1980;44:331-384. https://www.ncbi.nlm.nih.gov/pmc/ articles/PMC373181/

17. Ma Y, Marquis RE. Thermophysiology of Streptococcus mutans and related Lactic acid bacteria. Antonie Van Leeuwenhoek. 1997;72(2):91-100. https://www.ncbi.nlm.nih. gov/pubmed/9298187 DOI: 10.1023/a:1000290426248

18. Takada K, Hayashi K, Sasaki K, Sato T, Hirasawa M. Selectivity of MitisSalivarius agar and a new selective medium for oral Streptococci in dogs. J Microbiol Methods 2006;66(3):460-465.https://www.ncbi.nlm.nih.gov/ pubmed/16522335

19. Salminen S, Wright AV. Lactic Acid Bacteria: Microbiological and Functional Aspects. $3^{\text {th }}$ ed. Boca Raton FL: CRC Press 2004; 656 p

20. Rogosa M, Mitchell J, Wiseman R. A selective medium for the isolation and enumeration of oral and fecal Lactobacilli. J Bacteriol. 1951;62(1):132-3. https://www. ncbi.nlm.nih.gov/pubmed/14861168

21. Murry PR, Baronet EJ. Manual of Clinical Microbiology. $8^{\text {th }}$ ed. Washington D.C. American Society for Microbiology; 2003.

22. Sundas S, Rao A. Comparative evaluation of effect of chlorhexidine and sodium fluoride mouthwashes on plaque. J Nepal Health Res Counc. 2015;13(30):133-7. https://www.ncbi.nlm.nih.gov/pubmed/26744198

23. Haas AN, Reis A, Lemos CA, Pnnuti CM, Escobar E, Almeida ER. Daily biofilm control and oral health: An epidemiological challenge consensus - Brazilian advisory panel in oral health. Braz J Periodontol 2012;22(3):40-46. https://www.ncbi.nlm.nih.gov/pubmed/ 23318756

24. Renuka S, Muralidharan NP. Compraison in benefits of herbal mouthwashes with chlorhexidine mouthwash: A review. Asian J Pharm Clin Res 2017;10(2):3-7. https:// www.researchgate.net/publication/316506837

25. Shah S, Bargale S, Dave BH, Deshpande A, Kariya PB, Karri A. Comparison of antimicrobial efficacy of (between) $0.2 \%$ chlorhexidine and herbal mouthwash on salivary Streptococcus mutans: A randomized controlled pilot study. Contemp Clin Dent 2018;9(3): 440-445. https:// www.ncbi.nlm.nih.gov/pubmed/30166841 DOI: 10.4103/ ccd.ccd_264_18. 
26. Baig A, He T, Buisson J, Sagel L, Suszcynsky-Meister E, White DJ. Extrinsic whitening effects of sodium hexametaphosphate- A review including a dentifrice with stabilized stannous fluoride. Compend Contin Educ Dent 2005;26(1):4753. https://www.ncbi.nlm.nih.gov/pubmed/16999010

27. Arunachalam LT, Sudhakar U, Vasanth J, Khumukchum S, Selvam VV. Comparison of anti-plaque and anti-gingivitis effect of curcumin and chlorhexidine mouth rinse in the treatment of gingivitis: A clinical and biochemical study. J Indian Soc Periodontol 2017; 21(6):478-483. https://www. ncbi.nlm.nih.gov/pubmed/29551867

28. Bellamy PG, Khera N, Day TN, Barker ML, Mussett AJ. A randomized clinical trial to compare plaque inhibition of a sodium fluoride/potassium nitrate dentifrice versus a stabilized stannous fluoride/ sodium hexametaphosphate dentifrice. J Contemp Dent Pract 2009;10(2):1-9. https:// www.ncbi.nlm.nih.gov/pubmed/19279966

29. Mankodi S, Bartizek RD, Winston JL, Biesbrock AR, McClanahan SF,He T. Anti-gingivitis efficacy of a stabilized $0.454 \%$ Stannous Fluoride/Sodium Hexametaphosphate dentifrice: A controlled 6-month clinical trial. J Clin Periodontol 2005;32(1):75-80. https://www.ncbi.nlm.nih. gov/pubmed/15642062

30. Lanigan RS. Final report on the safety assessment of sodium metaphosphate, sodium trimetaphosphate, and sodium hexametaphosphate. Int J Toxicol 2001;20(3):75-89. https://www.ncbi.nlm.nih.gov/pubmed/11766135

31. Hacchou Y, Uematsu T, Ueda O, Usui Y, Uematsu S, Takahashi M, et al. Inorganic polyphosphate: A possible stimulant of bone formation. J Dent Res. 2007p;86(9):893-897. https://www.ncbi.nlm.nih.gov/pubmed/17720862

32. Murphy J, Beighton D, Clark D, Bartlett D. The potential for sodium hexametaphosphate (SHMP) found in common children drinks to limit acid production in the oral biofilm. J Dent 2007;35(3):214-217. https://www.ncbi.nlm.nih. gov/pubmed/16997450

33. Da Camara DM, Miyasaki ML, Danelon M, Sassaki KT, Delbem AC. Effect of low-fluoride toothpastes combined with hexametaphosphate on in vitro enamel demineralization. J Dent 2014;42(3):256-262. https://www.ncbi.nlm.nih.gov/ pubmed/24333957 DOI:10.1016/j.jdent.2013.12.002

34. Maier SK, Scherer S, Loessner MJ. Long-chain polyphosphate causes cell lysis and inhibits Bacillus cereus septum formation which is dependent on divalent cations. Appl Environ Microbiol 1999;65(9):3942-3949. https://www. ncbi.nlm.nih.gov/pubmed/10473399

35. Chambert R, Petit-Glatron MF. Anionic polymers of Bacillus subtilis cell wall modulate the folding rate of secreted proteins. FEMS Microbiol Lett 1999;179(1):43-47. https:// www.ncbi.nlm.nih.gov/pubmed/10481084. DOI: 10.1111/ j.1574-6968.1999.tb08705.x

36. Shibata H, Morioka T. Antibacterial action of condensed phosphates on the bacterium Streptococcus mutans and experimental caries in the hamster. Arch Oral Biol 1982;27(10):809816. https://www.ncbi.nlm.nih.gov/pubmed/6961893 DOI: 10.1016/0003-9969(82)90034-6

37. Knabel S, Walker H, Harman P. Inhibition of Aspergillus flavus and selected gram-positive bacteria by chelation of essential metal cations by polyphosphates. J Food Prot 1991;54(5):360-5. https://www.ncbi.nlm.nih.gov/ pubmed/31051558 DOI: 10.4315/0362-028X-54.5.360

38. Lee RM, Hartman PA, Stahr HM, Olson DG, Williams FD. Antibacterial mechanism of long-chain polyphosphates in Staphylococcus aureus. J Food Prot. 1994;57(4):289-294. https://www.ncbi.nlm.nih.gov/pubmed/31113131 DOI: 10.4315/0362-028X-57.4.289

39. Moon JH, Park JH, Lee JY. Antibacterial Action of Polyphosphate on Porphyromonas gingivalis. Antimicrob Agents Chemother. 2011;55(2):806-812. https://www.ncbi. nlm.nih.gov/pubmed/21098243 DOI: 10.1128/AAC.01014-10.

40. Da Camara DM, Pessan JP, Francati TM, Santos Souza JA, Danelon M, Delbem AC. Synergestic effect of fluoride and sodium hexametaphosphate in toothpaste on enamel demineralization in situ. J Dent 2015;43(10):1249-1254. https://www.ncbi.nlm.nih.gov/pubmed/26299931 DOI: 10.1016/j.jdent.2015.08.007

41. Post FJ, Krishnamurty GB, Flanagan MD. Influence of sodium hexametaphosphate on selected bacteria. Appl Microbiol. 1963;11:430-435. https://www.ncbi.nlm.nih. gov/pubmed/14063787

42. Obritsch JA, Ryu D, Lampila LE, Bullerman LB. Antibacterial effects of long-chain polyphosphates on selected spoilage and pathogenic bacteria. J Food Prot. 2008; 71(7):1401-1405. https://www.ncbi.nlm.nih.gov/ pubmed/18680939 DOI: 10.4315/0362-028x-71.7.1401 